\title{
Preprocessing Ground-Based Visible/Near Infrared Imaging Spectroscopy Data Affected by Smile Effects
}

\author{
Henning Buddenbaum ${ }^{1, *(\mathbb{D}}$, Michael S. Watt ${ }^{2}$, Rebecca C. Scholten ${ }^{1,3}{ }^{\mathbb{D}}$ and Joachim Hill ${ }^{1}$ \\ 1 Environmental Remote Sensing and Geoinformatics, Trier University, 54286 Trier, Germany; \\ r.c.scholten@vu.nl (R.C.S.); hillj@uni-trier.de (J.H.) \\ 2 Scion, 10 Kyle Street, Christchurch 8011, New Zealand; Michael.Watt@scionresearch.com \\ 3 Faculty of Earth and Life Sciences, Vrije Universiteit Amsterdam, 1081 HV Amsterdam, The Netherlands \\ * Correspondence: buddenbaum@uni-trier.de; Tel.: +49-651-201-4729
}

Received: 20 February 2019; Accepted: 26 March 2019; Published: 30 March 2019

\begin{abstract}
A data set of very high-resolution visible/near infrared hyperspectral images of young Pinus contorta trees was recorded to study the effects of herbicides on this invasive species. The camera was fixed on a frame while the potted trees were moved underneath on a conveyor belt. To account for changing illumination conditions, a white reference bar was included at the edge of each image line. Conventional preprocessing of the images, i.e., dividing measured values by values from the white reference bar in the same image line, failed and resulted in bad quality spectra with oscillation patterns that are most likely due to wavelength shifts across the sensor's field of view (smile effect). An additional hyperspectral data set of a Spectralon white reference panel could be used to characterize and correct the oscillations introduced by the division, resulting in a high quality spectra that document the effects of herbicides on the reflectance characteristics of coniferous trees. While the spectra of untreated trees remained constant over time, there were clear temporal changes in the spectra of trees treated with both herbicides. One herbicide worked within days, the other one within weeks. Ground-based imaging spectroscopy with meaningful preprocessing proved to be an appropriate tool for monitoring the effects of herbicides on potted plants.
\end{abstract}

Keywords: Specim FX10; field imaging spectroscopy; preprocessing; forestry; herbicide; invasive species

\section{Introduction}

To facilitate timber production in New Zealand, several coniferous tree species have been introduced from abroad. When they reproduce freely outside of plantations, they are considered invasive in their new environment [1,2]. In recent years, it has become evident that exotic trees are becoming invasive in many environments [3], and reports of their spread and adverse impacts have been reported from many regions [4]. The same evolutionary traits that make the introduced trees excellent timber species mean that they can often out-compete indigenous vegetation outside of their natural range [5]. Several conifer species including Pinus contorta (Dougl.), P. mugo Turra, P. nigra Arnold and Pseudotsuga menziesii (Mirb.) Franco have been spreading from commercial plantations, farm shelterbelts and woodlots for over 100 years into indigenous grasslands, shrublands, and even forested areas.

The area affected by invasive exotic conifers is thought to cover approximately 2 million ha and is believed to be increasing at a rate of $6 \%$ annually [6,7]. The level of infestation has resulted in an economic and ecological cost that is increasingly deemed to be unacceptable by New Zealand society [8]. The elimination of invasive exotic conifer over large areas with difficult terrain is partly reliant on aerial herbicide application. Detection of the impacts of herbicides on conifers would be of 
considerable use for determining the efficacy of applied herbicides so that these can be optimally used for control. The use of hyperspectral imagery could provide a useful means of pre-visual detection as this imagery allows a detailed assessment of the wavelengths that are most closely correlated with physiological change and needle necrosis [9-11].

In order to understand the effect of herbicide application on spectral properties of lodgepole pine (Pinus contorta (Douglas)) trees, a controlled experiment with potted wilding trees was conducted. Two-thirds of the trees were treated with two different herbicides and the remaining trees formed the untreated control group. Close-range hyperspectral images of the trees were captured using a visible/near infrared (VNIR) camera fixed on a frame about $2 \mathrm{~m}$ above ground and a conveyor belt that moved the trees under the camera. Six captures were recorded over a five-week period (Supplementary Materials, Figures S1-S6).

Hyperspectral imaging, also known as imaging spectroscopy, has been successfully employed in many scientific fields from several platforms like satellite [12], airplane [13], field setups [14] and in the laboratory [15], e.g., for the determination of biochemical foliar traits of tropical trees [16], for the classification of tree species and age classes [17], or to map soil organic carbon [18]. Yao et al. [19] used a laboratory hyperspectral camera to detect herbicide damage in soybean plants before it could be detected visually. Suarez et al. [20] used hyperspectral data to detect herbicide drift in cotton fields. Zhao et al. [21] inverted a physically-based reflectance model on spectroscopic leaf measurements to detect herbicide crop injury. Recent reviews on hyperspectral remote sensing can be found in [22-25].

The sensors record either uncalibrated digital numbers (DNs) or, if they are calibrated, radiance [26]. These are dependent on illumination, so the researchers are usually rather interested in reflectance, an inherent trait of the material recorded. Reflectance is the ratio of radiant exitance with irradiance. The ratio of the radiant flux reflected by a surface to that reflected into the same geometry by an ideal and diffuse (Lambertian) standard surface is called reflectance factor [26]; this can be measured with a downward-facing sensor and a white reference panel.

Many imaging spectrometers suffer from shifts of the wavelength position across the field of view [27-30]. This is called the "smile effect" because a plot of wavelength position against the sensor column is often shaped like a smiling mouth. The intensity of the smile effect varies with the wavelength and with the position of the pixel within the field of view. Although the smile effect is usually quite small in the raw data, it can have serious consequences on the reflectance spectra since the DN or radiance spectra are not smooth, due to narrow atmospheric absorption bands.

One advantage of field or laboratory imaging spectroscopy over airborne or space-borne data is that the transformation from DN or radiance to reflectance (atmospheric correction) can be much simpler, especially if a reference target is recorded within the images [31-35]. When each image column also contains pixels of the reference target, the transformation from radiance to reflectance factors can be calculated for each column separately and the wavelength shifts across the field of view do not create a problem [34,36]. In the case of quickly changing illumination conditions, it may be more advisable to include a white reference in each line instead of each column of the image. If the camera employed suffers from shifts of the wavelength position across the field of view (smile effect) $[27,28]$, the conversion from radiance to reflectance factors, through the division of measured values by the corresponding values of the white reference in the same image line, may fail and result in bad quality spectra. Here, we show that an additional capture of a white reference panel that covers the whole field of view of the camera can be used to characterize and correct these effects.

The objective of this research was to describe a method to robustly derive usable reflectance spectra from field imaging spectroscopy data affected by the smile effect. Within the materials and methods (Section 2), the herbicide experiment and the hyperspectral measurements are described. Then, the data analysis methods are presented, followed by the results (Section 3). Some short conclusions are drawn in Section 4. 


\section{Materials and Methods}

\subsection{Preparation of the Herbicide Experiment}

For the herbicide experiment, 39 Pinus contorta plants that did not show any signs of previous herbicide treatment, fungi or other infections were collected from the field in the central North Island of New Zealand between February and March 2017. Tree age, as estimated from the number of whorls, averaged four years and ranged from three to six years. Following collection, plants were placed in a greenhouse to acclimatise for the nine months preceding the trial. Plants were fertilised with phosphorus and nitrogen and irrigated as required over the duration of the experiment. At the start of the experiment tree height, root collar diameter and canopy width, respectively, averaged $157 \mathrm{~cm}$ (range 110-205 cm), $3.34 \mathrm{~cm}$ (range 2.17-5.10 cm) and 74.3 cm (range 48-135 cm).

Stratified random sampling based on the total tree height was used to allocate the 39 trees to the three treatments that included an untreated control and two herbicide treatments. The two herbicides applied included the systemic pyridine herbicide, triclopyr butoxyethyl ester (Grazon, $600 \mathrm{~g} \cdot \mathrm{L}^{-1}$ triclopyr, Dow AgroSciences Ltd., New Plymouth, New Zealand) and the contact herbicide diquat dibromide monohydrate (Reglone, $200 \mathrm{~g} \mathrm{~L}^{-1}$ diquat dibromide, Syngenta, Australia).

On 20 March 2018, the two herbicide treatments were applied using a calibrated boom sprayer, fitted with Turbo Teejet nozzles (TT8003; Spraying Systems Co. Wheaton, Illinois, USA) at a pressure of $2.6 \mathrm{kPa}$, and at a height of $2 \mathrm{~m}$ above the seedling canopy. These nozzles produced a spray characterised by droplets with a volume mean diameter (VMD) ranging from 350-500 $\mu \mathrm{m}$. After spraying, the trees were left to dry before being shifted back to the greenhouse on 21 March 2018, when the first imaging took place.

\subsection{Hyperspectral Imaging}

Hyperspectral measurements were conducted weekly before the treatment (capture 0) until five weeks after treatment (capture 5). A spectrograph-based Specim FX10 camera (Spectral Imaging Ltd., Oulu, Finland) was used to acquire the hyperspectral imagery. This instrument is a push-broom camera that captures 448 bands with wavelengths ranging from 400 to $1000 \mathrm{~nm}$ with a spectral sampling distance of $1.3 \mathrm{~nm}$ and a full width half maximum (FWHM) of $5.5 \mathrm{~nm}$. The spatial sampling comprises 1024 pixels (columns) within a field of view of $38^{\circ}$. The camera records one line at a time (scanner principle), and images are formed from the single lines through movement of either the camera or the target. The image acquisition was managed using the provided Lumo Recorder software interface. The camera is not calibrated, so it records DNs.

The camera was mounted on a tower-like construction about $2 \mathrm{~m}$ above ground, and a conveyor belt was used to move the plants through the field of view. The speed of the conveyor belt was adapted to fit the frame rate of the camera, which in turn was dependent on the exposure time, which had to be adjusted to the current illumination conditions. During the trial, the conveyor belt speed was kept constant and the frame rate was only adjusted to match the exposure time. A diffuse narrow white reference reflectance bar was attached at the edge of the field of view so that it was visible in every frame allowing changing illumination to be accounted for during postprocessing.

\subsection{Preliminary Smile Analysis}

A preliminary smile analysis was conducted using an image of a white reference panel which was illuminated by sunlight and covered the camera's complete field of view.

Eight wavelength regions with local minima in the signal due to atmospheric absorption or solar Fraunhofer lines were selected to characterize wavelength shifts. In each region, a second order polynomial was fitted to the data and the position of the minimum was found, separately for each of the 1024 sensor columns. If these minima were dependent on the sensor column, a wavelength shift was deemed to be present in the data. 


\subsection{Data Processing}

To transform the measured digital numbers (DN) values to reflectance factors (R), they have to be divided by the respective white reference DN (WR) at wavelength $\lambda$ [26]. In the case of the FX10 camera, the dark current has to be measured separately and subtracted from the signal [19,37]. For this purpose, a separate image with 100 lines is recorded while the camera shutter is closed. The mean of the 100 lines is calculated, resulting in a matrix of 1024 columns and 448 bands which can be subtracted from each image line. The resulting relative reflectance factor can be transformed into an absolute reflectance factor by multiplying the result with the reflectance of the white reference $R_{\lambda}^{\text {Ref }}[38]$ (Equation (1)):

$$
R_{\lambda}=R_{\lambda}^{R e f} \cdot\left(\frac{D N_{\lambda}-\operatorname{dark}_{\lambda}}{W R_{\lambda}-\operatorname{dark}_{\lambda}}\right) .
$$

Because of changing illumination conditions, each image line was corrected separately. As a first step, the pixels belonging to the white reference were identified; these were usually located around column 1000 of the 1024 image columns. The mean value of the five brightest pixels over the whole range of values was taken as WR in Equation (1).

This straightforward data processing scheme resulted in bad quality spectra that contained a wave pattern (pseudo reflectance). A simple solution to this problem was found when the white reference plate image that fills the camera's whole field of view was treated the same way. After dark current subtraction, the white reference image was divided by its own mean values of the columns covered by the white reference bar in the original image. This results in a line with a mean value close to one that contains the same wave pattern. Dividing $R_{\lambda}$ by this line results in corrected reflectance factors. A flowchart of the processing scheme is shown in Figure 1.

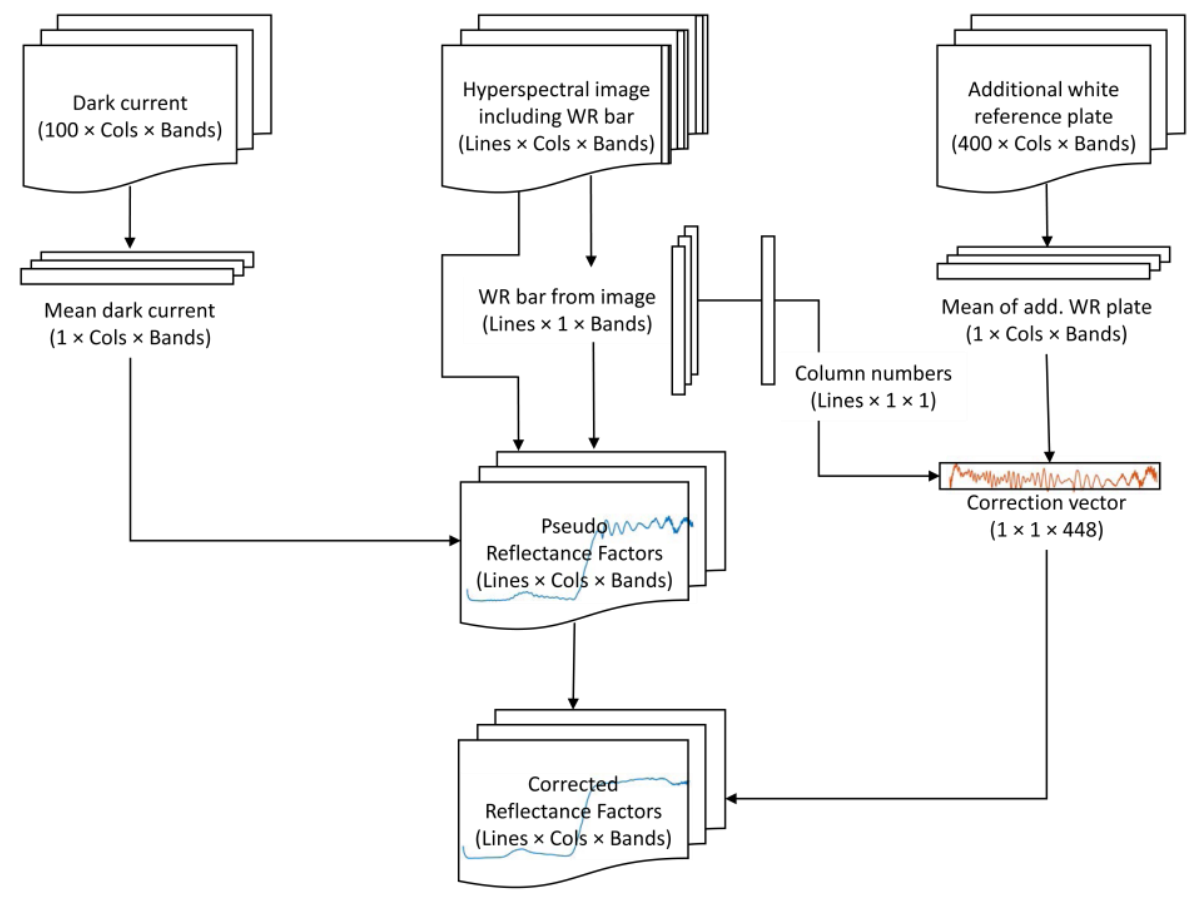

Figure 1. Data processing workflow: The mean dark current and white reference bar pixels of each line of the hyperspectral image are used to calculate pseudo reflectance factors. An additional hyperspectral data set of a white reference plate is transformed using the white reference bar pixel positions to create a correction vector which can be used to correct the pseudo reflectance data set. The size of each matrix is given. The camera employed in this study offers 1024 columns (cols) and 448 bands. The number of lines in the image and the image of the white reference plate are arbitrary. 
In a further step, the images were filtered using three criteria: Pixels with normalized difference vegetation index (NDVI) values greater than 0.4 , near infrared reflectance $(800 \mathrm{~nm})$ greater than 0.18 and blue reflectance $(460 \mathrm{~nm}$ ) less than 0.1 were accepted as vegetation pixels, the other pixels were masked out. Mean spectra of the trees were calculated as mean values of all vegetation pixels.

\section{Results and Discussion}

\subsection{Analysis of Smile Effects}

Results from the preliminary analysis of wavelength shifts are shown in Figure 2. For most absorption features examined, a smile shape displaying a clear minimum is evident. Due to the high number of local minima in the measured solar spectrum, the wavelength ranges of the selected features had to be quite narrow. For the first four features this leads to invalid values for column numbers greater than about 800 , since there the minimum wavelength is located outside the defined wavelength range of the feature. The magnitude of the wavelength shifts is quite small, usually in the range of 1-2 nm, which is in accordance with the manufacturer's calibration report. Still, this confirms that a treatment of smile effects may be necessary.
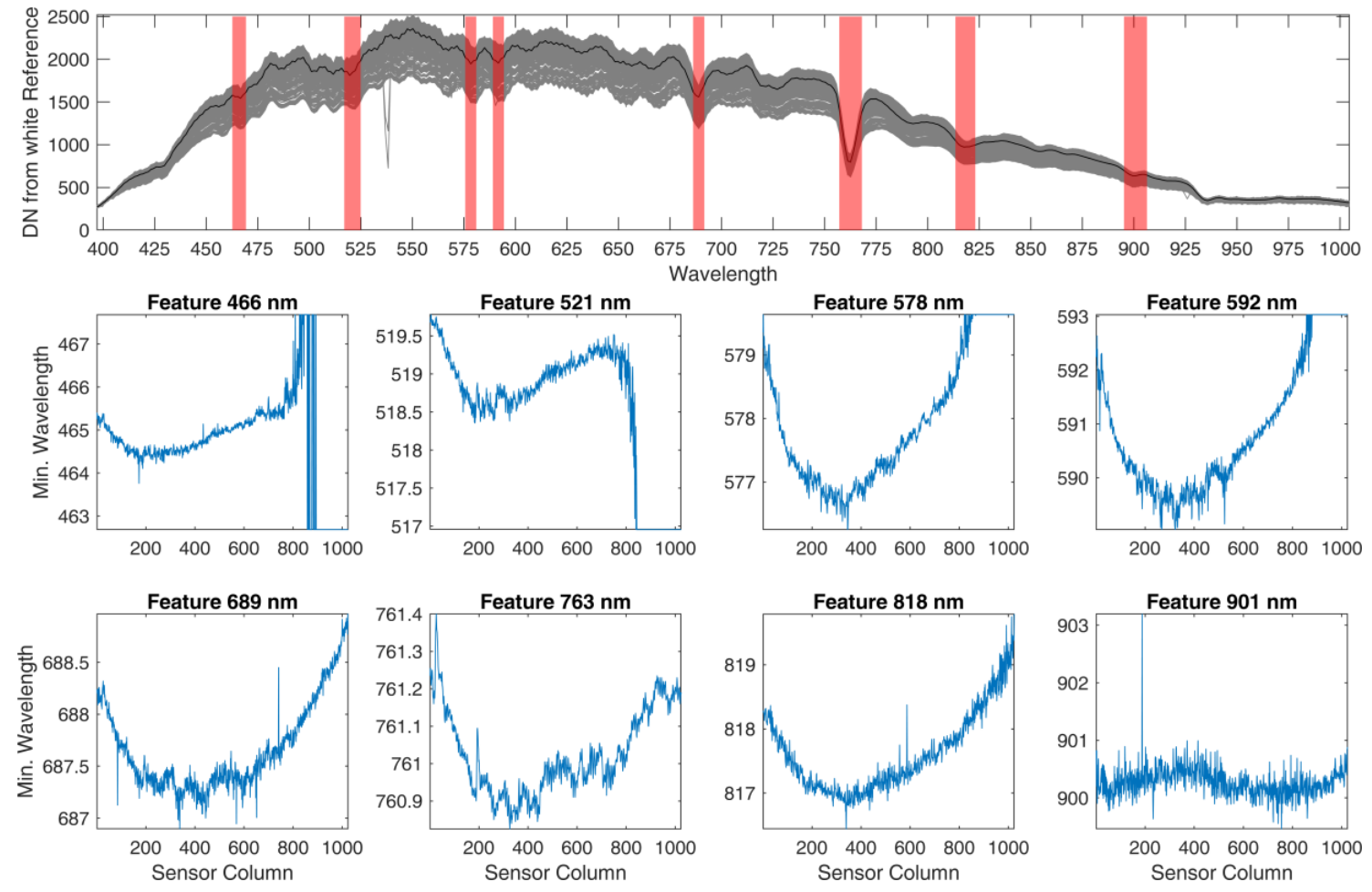

Figure 2. Analysis of sensor column dependent wavelength shifts. Top panel shows DNs of a measurement of sunlight reflected from a white reference panel (mean value in black and range given in gray). Eight wavelength positions with local minima are marked in red. The lower panels show the wavelength position of each minimum depending on the sensor column.

\subsection{Calculation of Reflectance Spectra}

Figure 3 shows the mean reflectance spectrum of the first capture of the first pot before and after correction of the wave pattern (mean of 53,700 pixels). The blue line in Figure 3a represents the ratio of vegetation pixels and the corresponding white reference bar pixels from the edge of the image. The red line is the ratio of white reference plate and pixels from the same edge position of the white reference plate image. This wave pattern mostly consists of an oscillation with oscillating amplitudes, with oscillation wavelengths increasing with spectral wavelength. Figure $3 \mathrm{~b}$ shows the corrected spectrum, 
the result of the ratio of the two aforementioned spectra. Only very small oscillations are left in the spectrum. Corrected spectra of all trees are shown in Figure 4. A striking difference between spectra from different capture days is the varying amount of noise in the spectral region of 900 to $1000 \mathrm{~nm}$. This can likely be explained by changing amounts of atmospheric water vapor between recording dates [39]. The quality of the spectra is high enough for further analysis of plant health and herbicide effects.

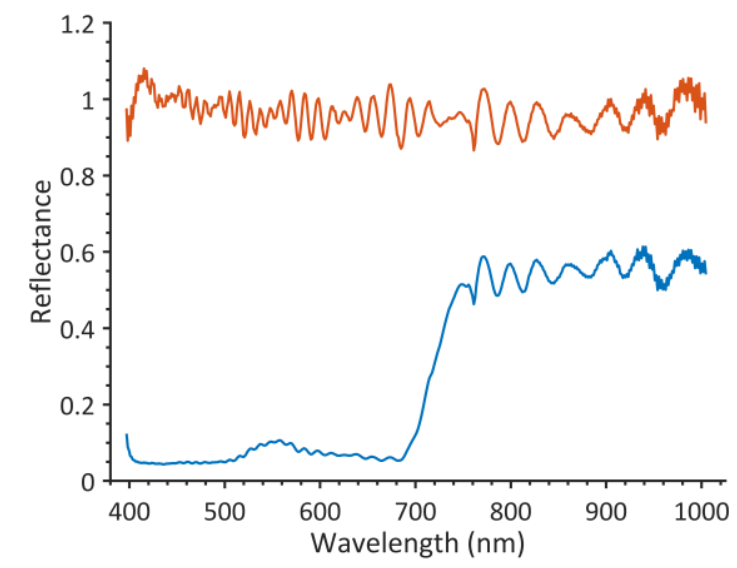

(a)

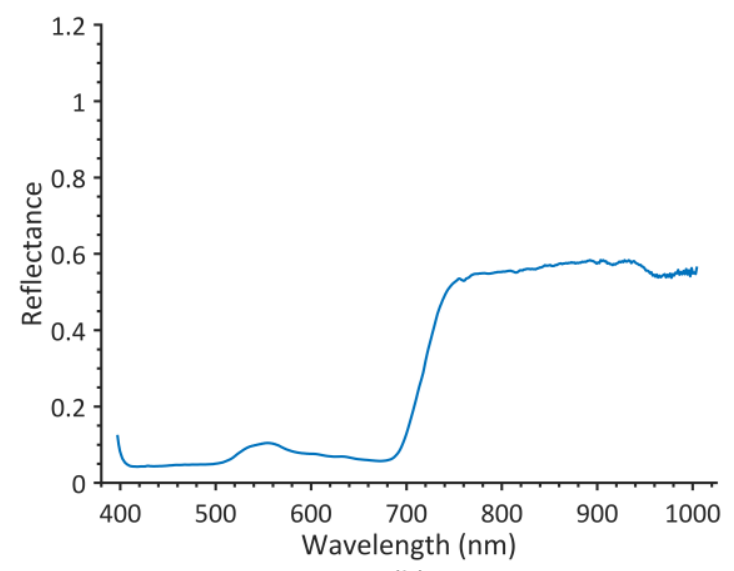

(b)

Figure 3. Calculation of reflectance spectra; (a) blue line shows the mean spectrum of a tree that results from division by white reference spectrum, red line shows the correction spectrum resulting from "correcting" an image of a white reference panel the same way; (b) corrected reflectance spectrum.

\subsection{Hyperspectral Images}

Images of good quality result from the preprocessing procedure described here. Some very slight striping is visible in the images [40], but no further steps were taken to compensate for this effect. Figure 5 shows the true color image time series for a selected tree from each treatment, which includes the control group, Diquat herbicide, and Triclopyr herbicide. The images show that Diquat very quickly turns the needles brown while Triclopyr works much more slowly. A detailed analysis of the herbicide effects is beyond the scope of this paper and will be the topic of another paper. 
Control
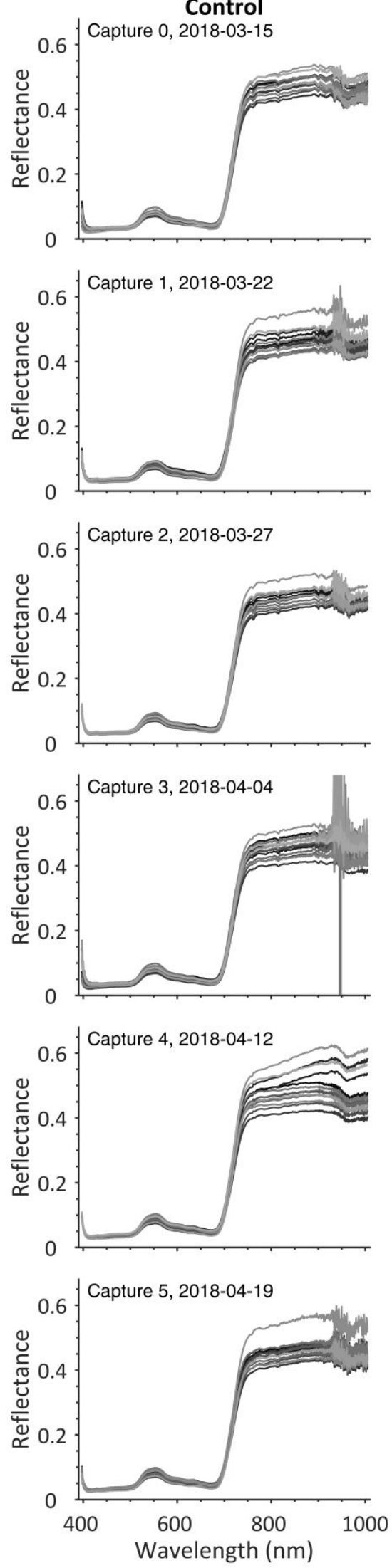
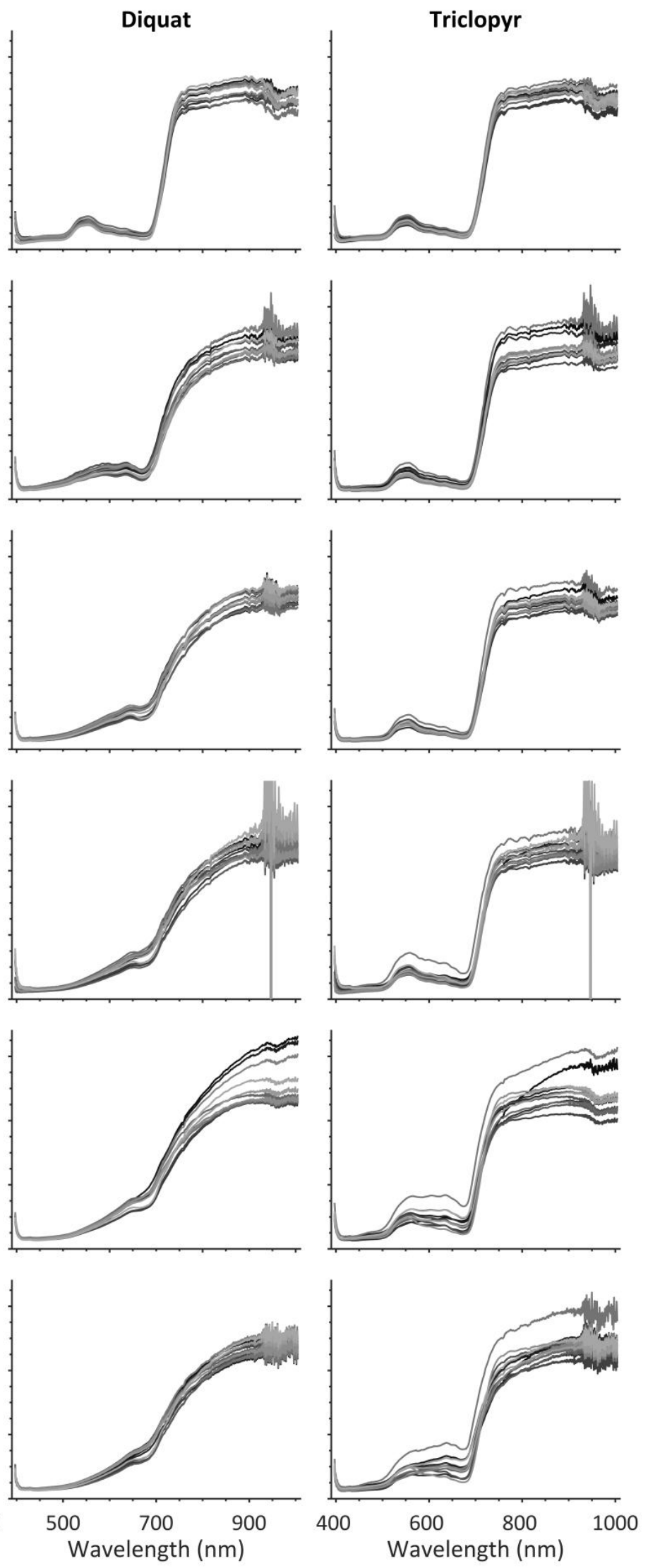

Figure 4. Corrected spectra of all trees. The left column contains the control group, the middle and right columns show the spectra of trees treated with herbicides. 

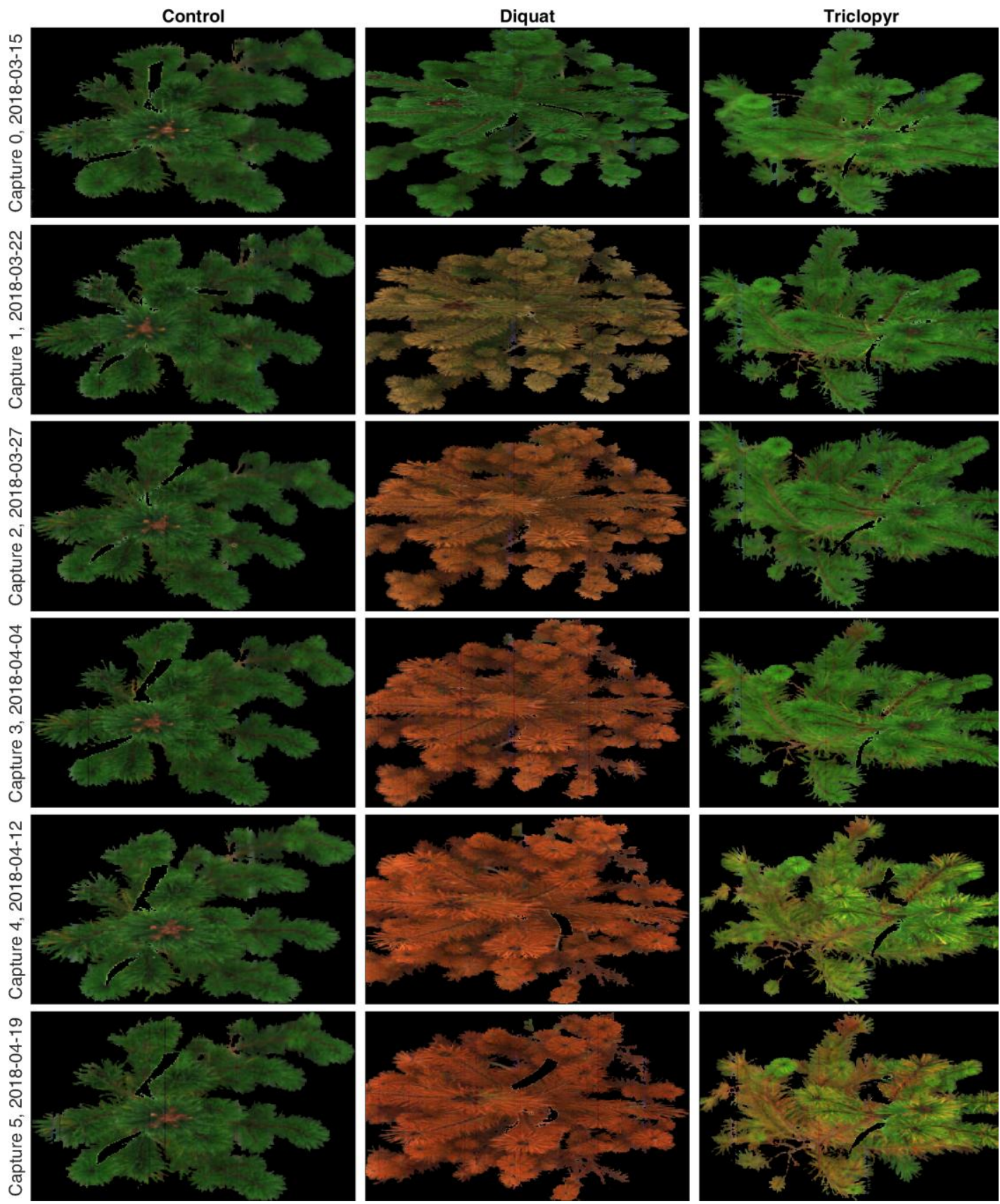

Figure 5. Time series imagery of an example tree from each treatment prior to treatment (Capture 0) and for the five weeks following treatment (Captures 1-5).

\section{Conclusions}

Close range imaging spectroscopy datasets of invasive conifers with and without herbicide treatment were recorded as a five-week time series. A white reference stick was included in every line of every image, but simple ratioing of vegetation pixels with white reference pixels did not lead to a satisfactory reflectance spectra. Instead, a correcting vector was calculated by ratioing a white reference measurement by pixels at the corresponding white reference columns identified in the original image. This approach may be helpful for comparable close-range spectroscopy applications and also for the radiometric correction of UAV-based imaging spectroscopy.

The resulting hyperspectral images will be used for analysis of the impact of herbicide treatments on the spectra of invasive conifers. 
Supplementary Materials: The following are available online at http:/ /www.mdpi.com/1424-8220/19/7/1543/ s1, Figure S1: True color depictions Capture 0, 2018-03-15; Figure S2: True color depictions Capture 1, 2018-03-22; Figure S3: True color depictions Capture 2, 2018-03-27; Figure S4: True color depictions Capture 3, 2018-04-04; Figure S5: True color depictions Capture 4, 2018-04-12; Figure S6: True color depictions Capture 5, 2018-04-19.

Author Contributions: Conceptualization, M.W.; Methodology, M.W., R.S., H.B.; Software, H.B.; Validation, H.B. and M.W.; Formal analysis, H.B.; Investigation, H.B.; Resources, M.W.; Data curation, H.B., R.S. and M.W.; Writing - original draft preparation, H.B.; Writing—review and editing, H.B., M.W., R.S. and J.H.; Visualization, H.B.; Supervision, M.W. and J.H.; Project administration, M.W.; Funding acquisition, M.W. and J.H.

Funding: This research was partly funded by the German Aerospace Center (DLR) and the German Federal Ministry of Economic Affairs and Energy in the framework of the EnMAP project, grant number 50 EE 1530. R.S. was supported by the DAAD-PROMOS program. The New Zealand funding for the project was obtained by the Winning Against Wildings programme (Contract Number C09X1611) funded by the New Zealand Ministry for Business, Innovation, and Employment. This funding was supplemented by co-funding from the Forest Growers Levy Trust and Scion's Strategic Science Investment Fund.

Acknowledgments: We are very grateful to Liam Wright for the wilding collection, and to Robin Hartley, Jonathan Dash, Grant Pearse, Honey Jane Estarija and Ben Morrow for their assistance during data collection. Many thanks to Jane Meiforth for helping organize the exchange between New Zealand and Germany.

Conflicts of Interest: The authors declare no conflict of interest. The funders had no role in the design of the study; in the collection, analysis, or interpretation of data; in the writing of the manuscript, or in the decision to publish the results.

\section{References}

1. Richardson, D.M.; Hui, C.; Nuñez, M.A.; Pauchard, A. Tree invasions: Patterns, processes, challenges and opportunities. Biol. Invasions 2014, 16, 473-481. [CrossRef]

2. Richardson, D.M.; Rejmanek, M. Conifers as invasive aliens: A global survey and predictive framework. Divers. Distrib. 2004, 10, 321-331. [CrossRef]

3. Richardson, D.M.; Rejmánek, M. Trees and shrubs as invasive alien species-A global review. Divers. Distrib. 2011, 17, 788-809. [CrossRef]

4. Nuñez, M.A.; Chiuffo, M.C.; Torres, A.; Paul, T.; Dimarco, R.D.; Raal, P.; Policelli, N.; Moyano, J.; García, R.A.; Wilgen, B.W.V.; et al. Ecology and management of invasive Pinaceae around the world: Progress and challenges. Biol. Invasions 2017, 19, 3099-3120. [CrossRef]

5. Farjon, A.; Farjon, A. A Natural History of Conifers; Timber Press: Portland, OR, USA, 2008.

6. Anonymous. The Right Tree in the Right Place-New Zealand Wilding Conifer Management Strategy 2015-2030; Ministry for Primary Industries: Wellington, New Zealand, 2011.

7. McAlpine, K.G.; Howell, C.J.; Wotton, D.M. Effects of tree control method, seed addition, and introduced mammal exclusion on seedling establishment in an invasive Pinus contorta forest. N. Z. J. Ecol. 2016, 40, 302-309. [CrossRef]

8. Dash, J.P.; Pearse, G.D.; Watt, M.S.; Paul, T. Combining Airborne Laser Scanning and Aerial Imagery Enhances Echo Classification for Invasive Conifer Detection. Remote Sens. 2017, 9, 156. [CrossRef]

9. Abdullah, H.; Darvishzadeh, R.; Skidmore, A.K.; Groen, T.A.; Heurich, M. European spruce bark beetle (Ips typographus, L.) green attack affects foliar reflectance and biochemical properties. Int. J. Appl. Earth Obs. Geoinf. 2018, 64, 199-209. [CrossRef]

10. Fassnacht, F.E.; Latifi, H.; Ghosh, A.; Joshi, P.K.; Koch, B. Assessing the potential of hyperspectral imagery to map bark beetle-induced tree mortality. Remote Sens. Environ. 2014, 140, 533-548. [CrossRef]

11. Niemann, K.O.; Quinn, G.; Stephen, R.; Visintini, F.; Parton, D. Hyperspectral Remote Sensing of Mountain Pine Beetle with an Emphasis on Previsual Assessment. Can. J. Remote Sens. 2015, 41, 191-202. [CrossRef]

12. George, R.; Padalia, H.; Kushwaha, S.P.S. Forest tree species discrimination in western Himalaya using EO-1 Hyperion. Int. J. Appl. Earth Obs. Geoinf. 2014, 28, 140-149. [CrossRef]

13. Green, R.O.; Painter, T.H.; Roberts, D.A.; Dozier, J. Measuring the expressed abundance of the three phases of water with an imaging spectrometer over melting snow. Water Resour. Res. 2006, 42. [CrossRef]

14. Jay, S.; Gorretta, N.; Morel, J.; Maupas, F.; Bendoula, R.; Rabatel, G.; Dutartre, D.; Comar, A.; Baret, F. Estimating leaf chlorophyll content in sugar beet canopies using millimeter- to centimeter-scale reflectance imagery. Remote Sens. Environ. 2017, 198, 173-186. [CrossRef] 
15. Steffens, M.; Kohlpaintner, M.; Buddenbaum, H. Fine spatial resolution mapping of soil organic matter quality in a Histosol profile. Eur. J. Soil Sci. 2014, 65, 827-839. [CrossRef]

16. Asner, G.P.; Martin, R.E.; Knapp, D.E.; Tupayachi, R.; Anderson, C.B.; Sinca, F.; Vaughn, N.R.; Llactayo, W. Airborne laser-guided imaging spectroscopy to map forest trait diversity and guide conservation. Science 2017, 355, 385. [CrossRef]

17. Buddenbaum, H.; Schlerf, M.; Hill, J. Classification of coniferous tree species and age classes using hyperspectral data and geostatistical methods. Int. J. Remote Sens. 2005, 26, 5453-5465. [CrossRef]

18. Hobley, E.; Steffens, M.; Bauke, S.L.; Kögel-Knabner, I. Hotspots of soil organic carbon storage revealed by laboratory hyperspectral imaging. Sci. Rep. 2018, 8, 13900. [CrossRef]

19. Yao, H.; Huang, Y.; Hruska, Z.; Thomson, S.J.; Reddy, K.N. Using vegetation index and modified derivative for early detection of soybean plant injury from glyphosate. Comput. Electron. Agric. 2012, 89, 145-157. [CrossRef]

20. Suarez, L.A.; Apan, A.; Werth, J. Hyperspectral sensing to detect the impact of herbicide drift on cotton growth and yield. ISPRS J. Photogramm. Remote Sens. 2016, 120, 65-76. [CrossRef]

21. Zhao, F.; Guo, Y.; Huang, Y.; Reddy, K.N.; Lee, M.A.; Fletcher, R.S.; Thomson, S.J. Early detection of crop injury from herbicide glyphosate by leaf biochemical parameter inversion. Int. J. Appl. Earth Obs. Geoinf. 2014, 31, 78-85. [CrossRef]

22. Hank, T.B.; Berger, K.; Bach, H.; Clevers, J.G.P.W.; Gitelson, A.; Zarco-Tejada, P.; Mauser, W. Spaceborne Imaging Spectroscopy for Sustainable Agriculture: Contributions and Challenges. Surv. Geophys. 2019, 40. [CrossRef]

23. Hill, J.; Buddenbaum, H.; Townsend, P.A. Imaging Spectroscopy of Forest Ecosystems: Perspectives for the Use of Space-borne Hyperspectral Earth Observation Systems. Surv. Geophys. 2019, 40. [CrossRef]

24. Verrelst, J.; Malenovský, Z.; Van der Tol, C.; Camps-Valls, G.; Gastellu-Etchegorry, J.P.; Lewis, P.; North, P.; Moreno, J. Quantifying Vegetation Biophysical Variables from Imaging Spectroscopy Data: A Review on Retrieval Methods. Surv. Geophys. 2019, 40. [CrossRef]

25. Gamon, J.A.; Somers, B.; Malenovský, Z.; Middleton, E.M.; Rascher, U.; Schaepman, M.E. Assessing Vegetation Function with Imaging Spectroscopy. Surv. Geophys. 2019, 40. [CrossRef]

26. Schaepman-Strub, G.; Schaepman, M.E.; Painter, T.H.; Dangel, S.; Martonchik, J.V. Reflectance quantities in optical remote sensing-definitions and case studies. Remote Sens. Environ. 2006, 103, 27-42. [CrossRef]

27. Guanter, L.; Estellés, V.; Moreno, J. Spectral calibration and atmospheric correction of ultra-fine spectral and spatial resolution remote sensing data. Application to CASI-1500 data. Remote Sens. Environ. 2007, 109, 54-65. [CrossRef]

28. Lenhard, K.; Baumgartner, A.; Schwarzmaier, T. Independent Laboratory Characterization of NEO HySpex Imaging Spectrometers VNIR-1600 and SWIR-320m-e. IEEE Trans. Geosci. Remote Sens. 2015, 53, 1828-1841. [CrossRef]

29. Gege, P.; Fries, J.; Haschberger, P.; Schötz, P.; Schwarzer, H.; Strobl, P.; Suhr, B.; Ulbrich, G.; Jan Vreeling, W. Calibration facility for airborne imaging spectrometers. ISPRS J. Photogramm. Remote Sens. 2009, 64, 387-397. [CrossRef]

30. Segl, K.; Guanter, L.; Kaufmann, H.; Schubert, J.; Kaiser, S.; Sang, B.; Hofer, S. Simulation of Spatial Sensor Characteristics in the Context of the EnMAP Hyperspectral Mission. IEEE Trans. Geosci. Remote Sens. 2010, 48, 3046-3054. [CrossRef]

31. Schläpfer, D.; Richter, R.; Feingersh, T. Operational BRDF Effects Correction for Wide-Field-of-View Optical Scanners (BREFCOR). IEEE Trans. Geosci. Remote Sens. 2015, 53, 1855-1864. [CrossRef]

32. Thompson, D.R.; Guanter, L.; Berk, A.; Gao, B.C.; Richter, R.; Schläpfer, D.; Thome, K.J. Retrieval of Atmospheric Parameters and Surface Reflectance from Visible and Shortwave Infrared Imaging Spectroscopy Data. Surv. Geophys. 2019, 40. [CrossRef]

33. Buddenbaum, H.; Stern, O.; Stellmes, M.; Stoffels, J.; Pueschel, P.; Hill, J.; Werner, W. Field Imaging Spectroscopy of Beech Seedlings under Dryness Stress. Remote Sens. 2012, 4, 3721-3740. [CrossRef]

34. Buddenbaum, H.; Steffens, M. Laboratory imaging spectroscopy of soil profiles. J. Spectr. Imaging 2011, 2. [CrossRef]

35. Rogass, C.; Koerting, F.M.; Mielke, C.; Brell, M.; Boesche, N.K.; Bade, M.; Hohmann, C. Translational Imaging Spectroscopy for Proximal Sensing. Sensors 2017, 17, 1857. [CrossRef] [PubMed] 
36. Steffens, M.; Buddenbaum, H. Laboratory imaging spectroscopy of a stagnic luvisol profile-High resolution soil characterisation, classification and mapping of elemental concentrations. Geoderma 2013, 195, 122-132. [CrossRef]

37. Pacheco-Labrador, J.; Martín, M.P. Characterization of a Field Spectroradiometer for Unattended Vegetation Monitoring. Key Sensor Models and Impacts on Reflectance. Sensors 2015, 15, 4154-4175. [CrossRef] [PubMed]

38. Peddle, D.R.; White, H.P.; Soffer, R.J.; Miller, J.R.; LeDrew, E.F. Reflectance processing of remote sensing spectroradiometer data. Comput. Geosci. 2001, 27, 203-213. [CrossRef]

39. Rodger, A. SODA: A new method of in-scene atmospheric water vapor estimation and post-flight spectral recalibration for hyperspectral sensors: Application to the HyMap sensor at two locations. Remote Sens. Environ. 2011, 115, 536-547. [CrossRef]

40. Rogaß, C.; Spengler, D.; Bochow, M.; Segl, K.; Lausch, A.; Doktor, D.; Roessner, S.; Behling, R.; Wetzel, H.U.; Kaufmann, H. Reduction of Radiometric Miscalibration-Applications to Pushbroom Sensors. Sensors 2011, 11, 6370-6395. [CrossRef] [PubMed]

(C) 2019 by the authors. Licensee MDPI, Basel, Switzerland. This article is an open access article distributed under the terms and conditions of the Creative Commons Attribution (CC BY) license (http:/ / creativecommons.org/licenses/by/4.0/). 